\title{
Posttraumatic chronic ossified extradural hematoma: a rare case report
}

\author{
Rakesh Kumar ${ }^{1}$, Radhe Shyam Mittal ${ }^{2}$ \\ Sawai Man Singh Medical College, Jaipur, Rajasthan, India \\ ${ }^{1}$ Registrar, Department of Neurosurgery \\ ${ }^{2}$ Professor \& Head Department of Neurosurgery
}

\begin{abstract}
Posttraumatic Chronic ossified extradural hematomas are rare entities. Natural absorption of EDH does not occurs due to calcification. Chronic ossified EDH is frequently present in paediatric age group. Careful regular follow-up is mandatory in conservatively managed case of $\mathrm{EDH}$ in children. We report a rare case of Posttraumatic Chronic ossified extradural hematomas in a 10-years old girl presenting six years after head injury with right temporal region swelling.
\end{abstract}

Key words: Chronic extradural hematoma, Ossification, head injury.

\section{Introduction}

Chronic ossified extradural hematomas are rare entities. Most of the reported cases are in paediatric age group [6]. Patients with good neurological state can be follow-up with computed tomography. In conservatively managed case of EDH in children careful follow-up is mandatory [12]. The mechanism of calcification of EDH is not well understood. We report a case of posttraumatic chronic ossified EDH in child presented with progressively increasing swelling in right temporal region since one year, having past history of fall from tree six years back..

\section{Case report}

A 10 years old female patient presented with complain of gradual progressive painless swelling in right temporal region since one year. On examination patient was conscious oriented without any neurological deficient. Patient vitals were stable. Her Complete blood count, coagulation profile, and serum biochemistry were in the normal range.

She had past history of fall from tree six years back, following that she developed swelling in right temporal region. Patient was treated by local doctor and as patient was conscious oriented, she was managed conservatively. No x-ray or CT scan head was done at that time. This swelling persisted in right temporal region without any symptom, so no medical advice was taken by patient. After increase in size of the swelling $\mathrm{x}$-ray skull was done by local doctor which shows calcification in right temporal region (Figure 
1). At our hospital CT scan head was done which revealed right temporal extradural heterogenous lesion with calcified walls (Figure 2). Craniectomy with excision of underlying bone and evacuation of hematoma was done. Liquefied altered blood with thick hard calcified walls adherent to duramater was present. On Histological examination of the specimen chronic ossified hematoma full of blood mixed fluid was confirmed. Patient was discharged on seventh postoperative day. Cranioplasty was done after six months by using bone cement.

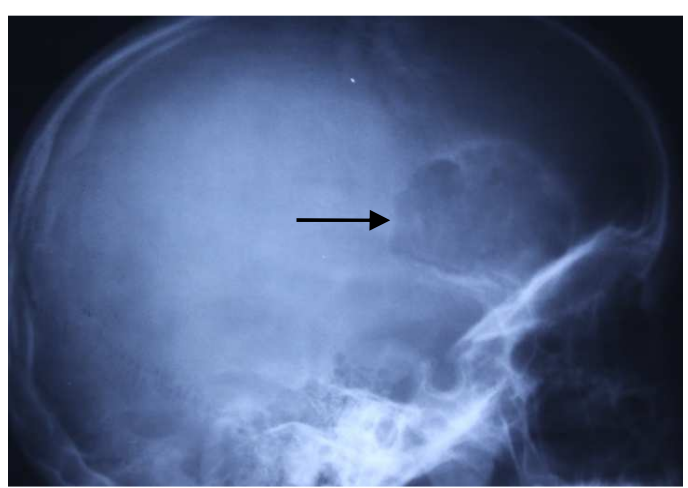

Figure1 - shows calcification in right temporal region (black arrow)

\section{Discussion}

The incidence of post traumatic EDH ranges from $2.7 \%$ to $4 \%$. $(4,5,6,9,10,11)$. Chronic EDH accounts for $3-30 \%$ of all epidural hematomas. Trauma being the most common cause, the other causes may be following neurosurgical procedures like shunt or posterior fossa surgery (1). Chronic extradural hematoma Calcification has been reported in literature as an isolated case report $(4,5,6,9,10,11)$.

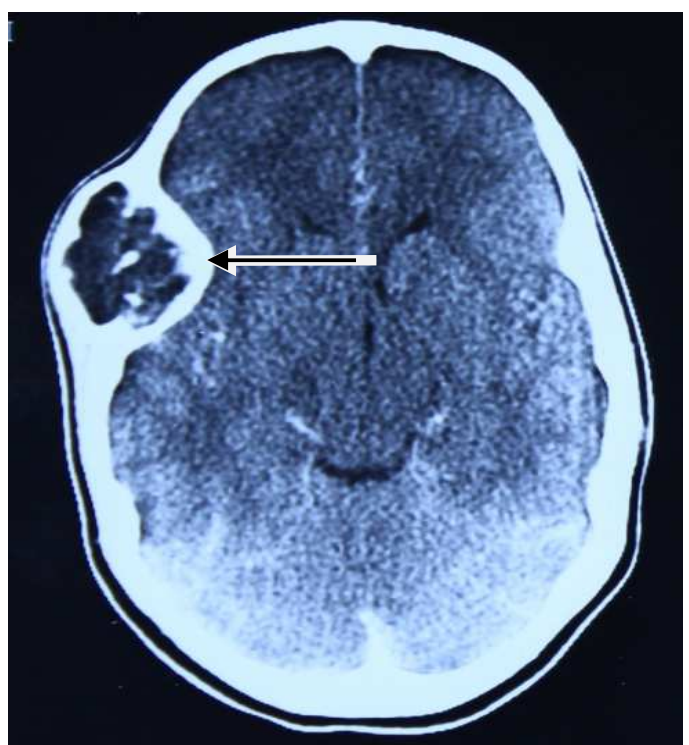

Figure 2 - shows right temporal extradural heterogenous lesion with calcified walls (black arrow)

Early calcification in traumatic EDH is extremely rare. Epidural hematoma may have various clinical presentation, mostly they present as neurosurgical emergencies requiring urgent surgical evacuation. Initially they may be asymptomatic, and may also enlarge producing pressure symptoms later. The usual symptoms are headache, seizure or may be asymptomatic. In paediatric age group, due to relatively firm adherence of dura to inner table and suture line the occurrence of $\mathrm{EDH}$ is unusual. In children, the $\mathrm{EDH}$ is of venous origin which takes longer time for accumulation of blood upto an adequate volume to cause significant mass effect and symptoms (8).In a case reported by kawata et al, ossification of EDH occurred 4 months and 12 days after head injury (7). Erdogen et al reported a case of epidural hematoma ossification within 10 days of injury in a 8 year old child (5). chang et al reported ossification of EDH 73 days after head injury with 
DOI: 10.2478/romneu-2014-0051

emphasis on surgical importance even if the patient condition is stable (4).The precise mechanism of calcification or ossification is uncertain. It has been hypothesized that vascularised tissue damage such as bone and dura provokes inflammation and remodelling in tissues (2).The natural sequence of healing is more rapid in children than adult. Meanwhile, EDH expansion may result from repeated bleeding of inner table of skull (8) or due to oozing from dural surface veins (13). Some authors presume that the ossification starts at junction between dura and hematoma capsule $(6,11)$. A characteristic intracranial, double outlined contour on plain skull $\mathrm{x}$-ray and CT scan represents bone formation and calcification of hematoma capsule adjacent to dura (3). For calcified EDH causing mass effect or neurological deterioration, surgical treatment in form of evacuation is recommended.

\section{Conclusion}

We conclude that while conservative management of EDH in children, regular follow up is mandatory. Calcification of EDH should be considered in children with persistent symptoms, seizures or neurological deterioration. Urgent evacuation of $\mathrm{EDH}$ should be considered for children with symptoms of mass effect or neurological deterioration.

\section{Correspondence}

Dr Radhe Shyam Mittal (MCh.)

Professor \& Head Of Department,

Department of Neurosurgery,

Sawai Man Singh Medical College,

Jaipur, Rajasthan, India, 302004.

E-mail: rksingh2226@gmail.com.

$$
\text { dr_mittal@hotmail.com }
$$

\section{Abbrebiations:}

EDH: Extradural hematoma

\section{References}

1. Bayri Y, Ulas A.K, Aykan U, Kaya A.H, Dagcinar A: Iatrogenic Chronic calcified/Ossified Epidural Hematoma: Case Report J Nervous Sys Surgery 2009; 2(2):91-94

2. Buckwalter JA, Cruess RL. Healing of the masculoskeletal tissues; In Rockwood CA, Green DP, Bucholz RW (eds):Fractures in adults, ed 3, Philadelphia, Lippincott 1991; vol1, pp 181-222.

3. Cambria S, Marra GA, Di Perri R, Bramanti P. Ossified epidural hematoma. Report of a case with epilepsy. J Neurosurg Sci 1985;29:285-8.15.

4. Chang JH, Choi JY, Chang JW, Park YG, Kim TS, Chung SS.Chronic Epidural hematoma with rapid ossification.Childs Nerv Syst 2002;18:712-6.

5. Erdogan B, Sen O, Bal N, Cekinmez M, Altinors N. Rapidly calcifying and ossifying epidural hematoma Pediatr Neurosurg 2003;39:208-11.

6. Iwakuma T, Brunngraber CV. Extradural ossification following an extradural hematoma.

J Neurosurg 1974;41:104-6.

7. Kawata Y, Kunimoto M, Sako K, Hashimoto M, Suzuki $\mathrm{N}$, Ohgami S,et al. Ossified epidural hematomas: Report of two cases. No Shinkei Geka 1994;22:51-4.

8. Kaye EM, Cass PR, Dooling E, Rosman NP. Chronic epidural hematomas in childhood: Increased recognition and non-surgical management. Pediatr Neurol 1985;1:255-9.

9. Leclercq TA,Rozycki T. Chronic calcified epidural hematoma in a child RI Med J 1979; 62, 97-9.

10. Mathuriya SN, Kak VK, Banerjee AK. Ossified epidural hematomas: Report of two cases.Clin Neurol Neurosurg 1989; 91:269-72.

11 Nagane M, Oyama H, Shibui S, Nomura K, Nakanishi Y,Kamiya M. Ossified \&calcified epidural hematoma incidentally found 40 years after head injury: Case report.Surg Neurol 1994; 42: 65-69..

12. Pang D, Horton JA, Herron JM, Wilberger JE Jr, Vries JK. Nonsurgical management of extradural hematomas in children. J Neurosurg 1983;59:958-71.

13. Raimondi AJ: Trauma; In Raimondi AJ (eds): Pediatric Neurosurgery, New York, Springer, 1987; pp 343-377. 